\title{
Verification of simplified gait analysis
}

Civil Engineering $\quad$ Rita M. Kiss / László Kocsis

$53 / 1$ (2009) 9

doi: 10.3311/pp.ci.2009-1.02

web: http://www.pp.bme.hu/ci

(c) Periodica Polytechnica 2009

RESEARCH ARTICLE
Received 2008-10-17, accepted 2008-12-15

\begin{abstract}
In this study we describe a simplified gait analysis system for the estimation of spatial-temporal parameters and kinetic parameters during walking on an instrumented treadmill. This method proposes to compute the values of temporal (length of double support phase, length of stance phase, time of step, time of stride) and few spatial parameters (step length, stride length, cadence) from the graph of time vs. ground reaction force at a constant gait speed. The method was verified by a clinical gait analysis method using a ZEBRIS ultrasound-based measuring system with ARMMODEL software, and the measurement error rate of the method was determined by statistical calculations. The maximum relative value of the average difference of temporal parameters is $0.79 \%$ in cycle time and that of spatial parameters is $0.66 \%$. On the basis of statistical analysis, it can be established that the measurement method is reproducible. This system is simple, inexpensive and does not provoke any discomfort to subjects. It can be carried on for long periods of time during a treadmill walk, thus providing new longitudinal information such as the stride-to-stride variability of gait. Several clinical applications can be proposed such as outcome evaluation after different orthopaedical, rheumatological, neurological diseases, and monitoring of the rehabilitation process.
\end{abstract}

\section{Keywords}

Biomechanics $\cdot$ gait analysis $\cdot$ verification $\cdot$ spatial-temporal parameters

\section{Acknowledgement}

The research described in this paper was supported by a grant from the National Scientific Research Fund (OTKA), Hungary, project No: T049471. Special thanks to Róbert Paróczai MSc, Árpád Illyés PhD, MD and Mátyás Magyar MD for their help in the completion of measurements.

\section{Rita M. Kiss}

Department of Structure, BME, H-1111. Budapest, Bertalan Lajos 2, Hungary e-mail: kissrit@t-online.hu

\section{László Kocsis}

Department of Applied Mechanics, H-1111 Budapest, Múegy. rkp 9, Hungary e-mail: kocsis@mm.bme.hu

\section{Introduction}

Walking is one of the most common human physical activities. Gait analysis can be described as a field of biomechanical engineering dealing with the subject of human locomotion. By means of different available measuring techniques (opticalbased, electromagnetic-based, or ultrasound-based), the data of human gait are captured and further analysis and calculation are performed in order to obtain all the data required for evaluating the quality of the subject's gait, including basic gait parameters (spatial-temporal, angular, kinetic parameters), forces and moments occurring in the joints, muscle activity during each gait cycle, velocity and acceleration of each segment of the limb, etc. A complete gait analysis requires a dedicated laboratory with a measuring system, treadmill and electromyography. The evaluation of gait parameters during walking is helpful in assessing abnormal gait, in quantifying improvements resulting from intervention, or in predicting subsequent events such as ageing or falls. Since ultrasound-based measuring and recording techniques were developed, gait analysis has been frequently used in almost all fields of human locomotion [7,9]. An ultrasoundbased measuring system is used for functional performance assessment after treatment or surgery [2, 3, 10,11$]$.

Although the dedicated gait laboratory has been widely used in sport applications, post-injury assessment, disability evaluations, research analysis of injuries, industrial applications of sports product design and improvement, etc., their sophistication, the time required for setting up the instrumentation and analyzing the data as well as their costs have hindered their use in clinical practice. To avoid this limitation, a new simplified gait analysis method is developed for everyday clinical practice.

The use of optical-based, electromagnetic-based or ultrasound-based systems in human movement analysis requires determination of the position of active or passive markers on anatomical points or body segments before the calculation of the kinematics and kinetics of body segments. Disadvantages of this method include the expensiveness of instrumentation, the long time required for setting-up the instrumentation, for post-processing and calculation of the gait parameters. The markers attached to the investigated person 
may be an unfamiliar experience, which may influence the parameters measured.

Our simplified gait analysis uses an instrumented treadmill to detect the ground reaction force in function of time during walking. The investigated person walks on the treadmill with a constant gait speed. This method proposes to compute the values of temporal gait parameters (length of double support phase, length of stance phase, time of step, time of stride) from the graph of time vs. ground reaction force. Spatial parameters (step length, stride length, cadence) can be calculated from temporal parameters and from the constant gait speed of walking. Simplified gait analysis does not require special instrumentation to be attached to the investigated persons.

The goal of this research is to present a validation of simplified gait analysis by the ARMMODEL measuring method with a ZEBRIS ultrasound-based measuring system [7].

\section{Subject and method}

\subsection{Subject}

The study population consisted of 45 healthy subjects using the method to be described below. Only people without any clinical history of diseases or injuries in the lower extremities were involved in the study. There were 23 males (mean age $23.17 \pm 9.09$ years, mean height $172.42 \pm 3.11 \mathrm{~cm}$, mean weight $73.12 \pm 15.88 \mathrm{~kg}$ ) and 22 females (mean age $26.99 \pm 8.21$ years, mean height $167.97 \pm 8.70 \mathrm{~cm}$, mean weight $61.23 \pm 7.38 \mathrm{~kg}$ ). The tests were authorized by the Science and Research Ethics Committee of Semmelweis University. Each voluntary subject provided an informed written consent to performing the tests in advance.

\subsection{Method of simplified gait analysis}

\subsubsection{Apparatus}

The basic system consists of an instrumented treadmill ergometer (Bonte Zwolle B.V. Austria) with two built-in force plates; the walking area of the treadmill belt is $330 \mathrm{~mm} \times 1430$ mm (Fig. 11). The instrument and the PC are linked via a USB interface. The zebris WINDATA or WINGAIT measuring program collects the vertical components of the ground reaction force during gait. The measurement frequency is $1000 \mathrm{~Hz}$.

\subsubsection{Procedure}

The subjects - in everyday clothes and without shoes - walked on a motorized treadmill. The treadmill was set at a constant speed. Walking on the treadmill can initially be an unfamiliar experience. This in turn can influence the parameters measured. Therefore, the measurement starts after six minutes of familiarization time as suggested by Alton et al [1] and Matsas et al[12]. The measuring program collected the vertical components of the ground reaction force during at least six gait cycles (Fig. 2).

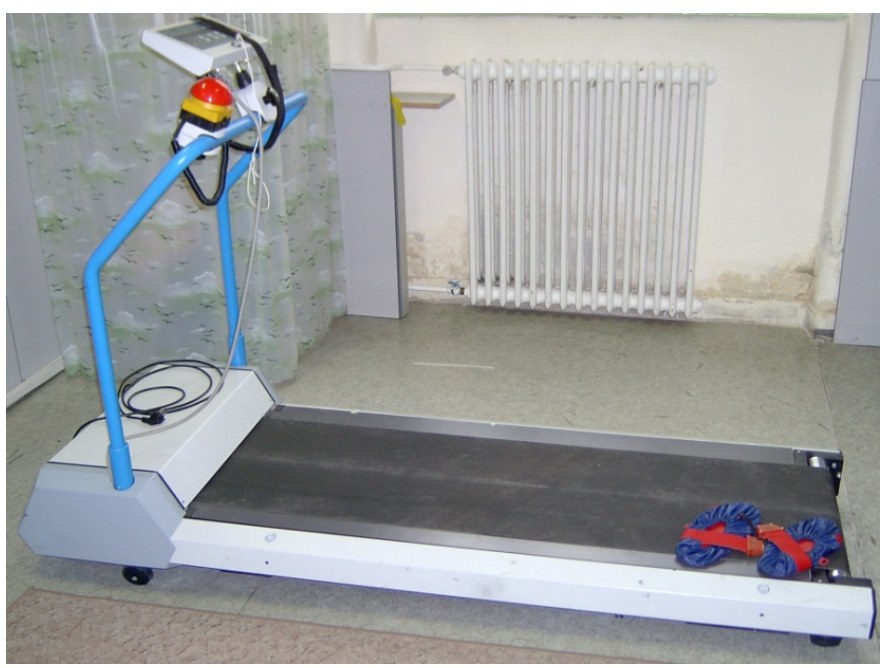

Fig. 1. Instrumented treadmill ergometer (Bonte Zwolle B.V. Austria)

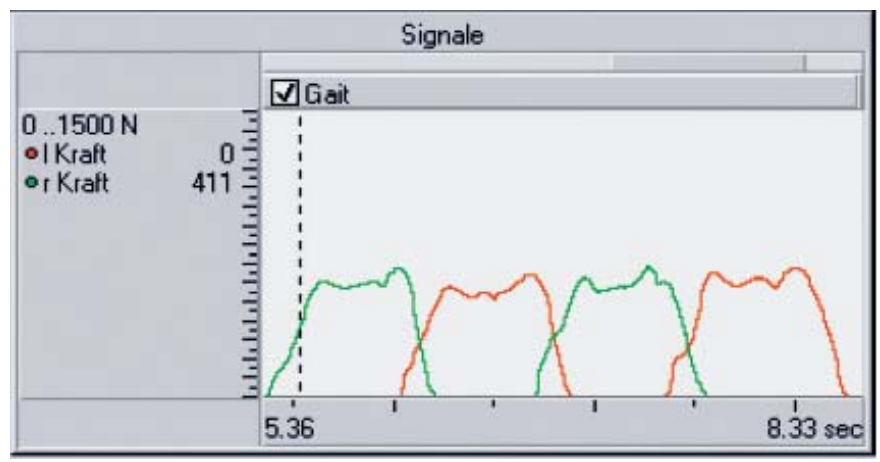

Fig. 2. Collected ground reaction force in function of time

\subsubsection{Assessment parameters}

During the analysis of the data collected (Fig. 2), the following kinetic parameters are calculated (Fig. 3):

- normalized ground reaction force [\% body weight] in function of time

- the first peak force $\left[F_{1}-\%\right.$ bw] in the early stance phase (in percentage of body weight)

- the second peak force $\left[F_{2}-\% b w\right]$ in the middle stance phase (in percentage of body weight)

- the third peak force $\left[F_{3}-\%\right.$ bw] in the late stance phase (in percentage of body weight)

- the rise of loading response $[\alpha]$

- the rise of loading of preswing $[\beta]$.

The temporal parameters calculated from the ground reaction force in function of time (Fig. 4) are as follows:

- length of stance phase (stance time) $\left[t_{\text {stance }}-\mathrm{s}\right]$

- length of swing phase (swing time) $\left[t_{\text {swing }}-\mathrm{s}\right]$

- length of double support phase $\left[t_{d o u b l e}-\mathrm{s}\right]$

- time of step $\left[t_{\text {step }}-\mathrm{s}\right]$ 


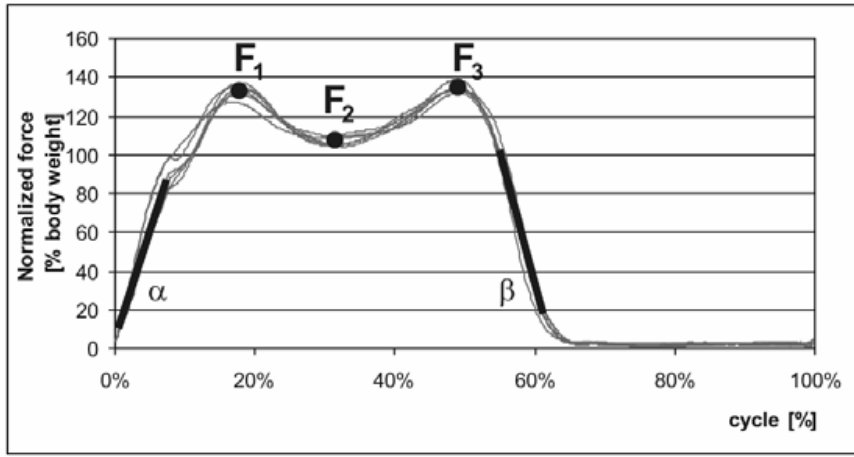

Fig. 3. Normalized ground reaction force in function of time and the definition of kinetical parameters

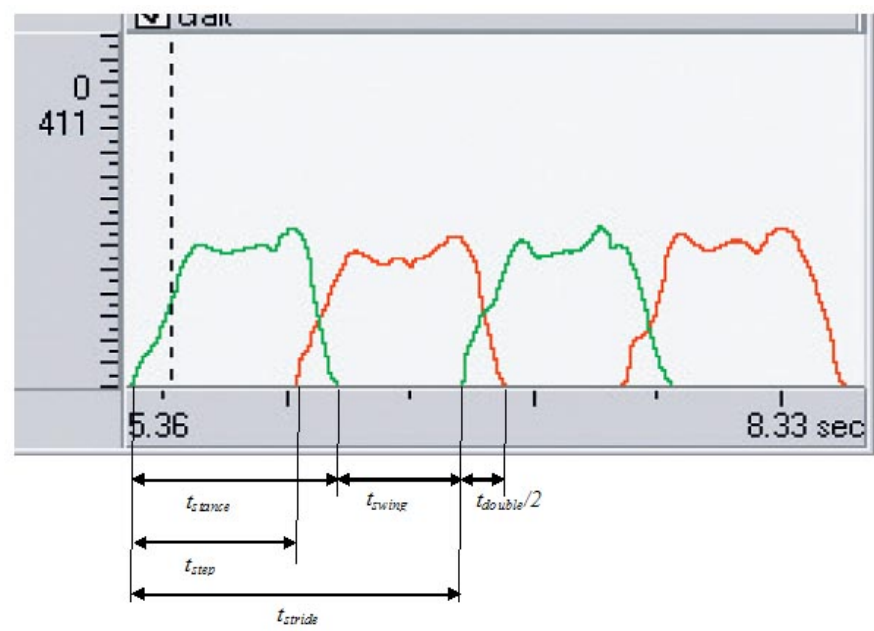

Fig. 4. Temporal parameters calculated from the graph of ground reaction force vs. time

The spatial parameters calculated from temporal parameters and constant gait speed $\left[v_{\text {gait }}-\mathrm{m} / \mathrm{s}\right]$ are as follows:

- cadence [c - step/minutes]

$$
c=\frac{120}{t_{\text {stride }}}
$$

- step length $\left[l_{\text {step }}-\mathrm{mm}\right]$

$$
l_{\text {step }}=v_{\text {gait }} \cdot t_{\text {step }} \cdot 1000
$$

- stride length $\left[l_{\text {stride }}-\mathrm{mm}\right]$

$$
l_{\text {stride }}=v_{\text {gait }} \cdot t_{\text {stride }} \cdot 1000
$$

\subsection{Method of verification}

The new, simplified gait analysis was validated by clinical gait analysis, consisting of the ARMMODEL measuring method with a ZEBRIS ultrasound-based measuring system [7].

\subsubsection{Clinical gait analysis using a Zebris ultrasound- based system}

The spatial coordinates of anatomical points were collected using an ultrasound-based ZEBRIS CMS-HS system (ZEBRIS, Medizintechnik GmbH, Germany). The measuring head with

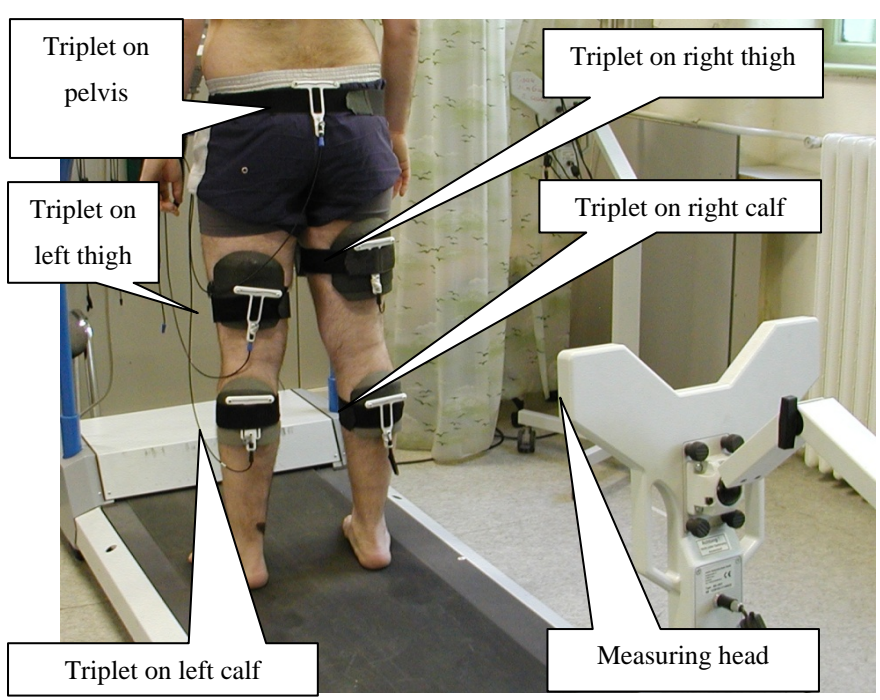

Fig. 5. Measuring arrangement by Zebris ultrasound-based system

three sensors is positioned behind the individual and the five ultrasound-based triplets with three active markers on each are placed on the sacrum, the left and right thighs, and the left and right calves (Fig. 5). The core tenet of the approach is that the orientation and position of a segment of the human body is determined by the position of three points per segment. The three active markers of a triplet produce a segment-embedded reference-frame [7]. A minimum of three points were selected on each segment to describe the motion of the rigid segment. The position of investigated anatomical points (e.g. the medial and lateral malleolus, the heel, the head of the fibula, the tibial tubercle, the medial and lateral femoral epicondyle, the greater trochanter, the left and right anterior superior iliac spine and processus spinosous of vertebrae sacralis) in the segment-embedded reference frame should be determined before measurement by the ultrasound-based pointer [7]. The selected anatomical points are palpable through the skin. The position of the three basis points (active markers on triplets) of each segment of the human body is to be measured during motion by the ultrasound-based device. The position of anatomical points can be calculated from the co-ordinates of active markers on triplets and from the position of the investigated points in the segment-embedded reference frame on-line [8]. Data were collected at a frequency of $100 \mathrm{~Hz}$. The measuring method was described in detail in [8]. The absolute error of our ultrasound-based system is less than $1 \mathrm{~mm}[5]$. The time of heel strike and toe-off are calculated from the spatial coordinates of the heel and the sacrum, as the maximum and minimum displacement of the heel from the sacrum [3]. From these parameters the following temporal and spatial parameters are calculated:

- length of stance phase (stance time)

- length of swing phase (swing time)

- length of double support phase

- cadence 
- step length

- stride length.

\subsubsection{Measurement protocol of verification}

The main steps of the 40 to 50 minute measurement are as follows:

- A triplet is fastened to each of the sacrum, the left and right thighs and the left and right calves (Fig. 5), and connected to the measurement system using cables and the data capture unit according to channel distribution.

- In the course of calibration, the person performing the test uses the ultrasound-based pointer to identify anatomical points and record the position vector of the anatomical points in the local coordinate system defined by the triplets.

- The measurement starts after six minutes of familiarization time [1, 12].

- The measurement was performed at four different gait speeds $(2.0,3.0$ and $4.0 \mathrm{~km} / \mathrm{h}$, which is $0.55,0.833$ and $1.11 \mathrm{~m} / \mathrm{s})$. The spatial coordinates of anatomical points and the vertical component of the reaction force were collected and recorded by the measurement control software for six gait cycles.

\subsubsection{Calculation of parameters for verification}

The raw data (the coordinates of each investigated anatomical point and ground reaction force) were smoothed and filtered using a fourth-order zero lag digital Butterworth with high frequency cut-off at $5 \mathrm{~Hz}$. The following spatial-temporal parameters are calculated from the anatomical points [3] and from the ground reaction force in function of time (see 2.2.3 Eqs (1-3)):

- length of stance phase (stance time)

- length of swing phase (swing time)

- length of double support phase

- cadence

- step length

- stride length.

In order to identify the accuracy of the new method, calculations were made on the average of the difference between the spatial-temporal parameters, which were determined by two different methods, as well as on the width of $95 \%$ confidence intervals and the correlation confidence between the two data sets.

\section{Results}

For the sake of transparency, the results of error calculations are summarized in Table 1. Statistical features are determined separately for each of the three gait speeds.

Table 1 shows the difference between the spatial -temporal parameters determined by the two post-processing methods, the width of the $95 \%$ confidence interval and the correlation confidence between the two data sets. The maximum values of the average absolute (relative) difference are 0.57 percent of cycle time $(0.79 \%)$ in case of the length of the stance phase, 0.31 percent of cycle time $(0.86 \%)$ in case of the length of the swing phase, and 0.17 percent of cycle time $(0.63 \%)$ in case of the length of the double support phase. The maximum values of the average absolute (relative) difference are 0.71 steps per minutes $(0.82 \%)$ in case of cadence, $0.4 .61 \mathrm{~mm}(0.57 \%)$ in case of step length, $7.98 \mathrm{~mm}(0.59 \%)$ in case of stride length. The correlation confidence is over 0.90 in all cases.

\section{Discussion}

The simplified gait analysis technique presented in this study is capable of reliably measuring spatial-temporal and kinetical parameters in gait. Spatial-temporal parameters can be determined from the ground reaction force in function of time measured at constant gait speed on an instrumented treadmill. The method was verified by the ultrasound-based measuring and post-processing (calculation) method verified earlier [5, 7, 8], which calculates temporal and spatial parameters from the spatial coordinates of anatomical points.

On the basis of the statistical analysis of temporal and spatial parameters (Table 1), it can be established that the measuring and calculation method is reproducible because in case of temporal parameters determined from the ground reaction force in function of time the maximum absolute difference is around 0.50 percent of cycle time, the relative error is below $1 \%$, and the minimal value of correlation confidence is 0.90 . In case of spatial parameters calculated from temporal parameters and the gait speed, the maximum absolute difference is $7.98 \mathrm{~mm}$, the relative error is around $0.50 \%$, and the minimal value of correlation confidence is 0.91 .

The analysis of the results also shows that the values of relative errors are nearly identical at various parameters; the speed of gait does not substantially affect the value of absolute and relative errors, either. The results of correlation confidence show that there is no significant difference between the two calculation methods; correlation between the two data sets is high, almost excellent.

In conclusion, the new measuring and post-processing (calculation) method determined the kinetic parameters and the temporal and spatial gait parameters from the ground reaction force in function of time during constant speed gait on an instrumented treadmill. Verification studies suggest that the method is reliable. On the basis of the results yielded, it can be established that simplified gait analysis can be used for describing the spatial and temporal parameters for both healthy and injured subjects. When compared to other methods, our technique presents some advantages: 
Tab. 1. Statistical parameters (absolute and relative difference, $95 \%$ confidence and correlation confidence) of spatial-temporal parameters specified from the spatial coordinates of anatomical points and from the graph of ground reaction force vs. time at different gaits.

\begin{tabular}{|c|c|c|c|c|c|c|c|c|c|c|}
\hline \multirow[t]{3}{*}{ Parameters } & \multirow[t]{3}{*}{ Unit } & \multicolumn{9}{|c|}{ Speed of gait } \\
\hline & & \multicolumn{3}{|c|}{$2 \mathrm{~km} / \mathrm{h}$} & \multicolumn{3}{|c|}{$3 \mathrm{~km} / \mathrm{h}$} & \multicolumn{3}{|c|}{$4 \mathrm{~km} / \mathrm{h}$} \\
\hline & & $\begin{array}{l}\text { Average } \\
\text { absolute } \\
\text { (relative) } \\
\text { difference }\end{array}$ & $\begin{array}{c}95 \% \\
\text { confidence }\end{array}$ & $\begin{array}{c}\text { correlation } \\
\text { confidence } \\
\qquad\left(R^{2}\right)\end{array}$ & $\begin{array}{l}\text { Average } \\
\text { absolute } \\
\text { (relative) } \\
\text { difference }\end{array}$ & $\begin{array}{c}95 \% \\
\text { confidence }\end{array}$ & $\begin{array}{c}\text { correlation } \\
\text { confidence } \\
\qquad\left(R^{2}\right)\end{array}$ & $\begin{array}{l}\text { Average } \\
\text { absolute } \\
\text { (relative) } \\
\text { difference }\end{array}$ & $\begin{array}{c}95 \% \\
\text { confidence }\end{array}$ & $\begin{array}{c}\text { correlation } \\
\text { confidence } \\
\left(R^{2}\right)\end{array}$ \\
\hline $\begin{array}{l}\text { Length of } \\
\text { stance phase }\end{array}$ & $\begin{array}{l}\text { percent of } \\
\text { cycle time }\end{array}$ & $\begin{array}{c}0.57 \\
(0.72 \%)\end{array}$ & 0.61 & 0.92 & $\begin{array}{c}0.53 \\
(0.79 \%)\end{array}$ & 0.56 & 0.90 & $\begin{array}{c}0.46 \\
(0.72 \%)\end{array}$ & 0.49 & 0.92 \\
\hline $\begin{array}{l}\text { Length of } \\
\text { swing phase }\end{array}$ & $\begin{array}{l}\text { percent of } \\
\text { cycle time }\end{array}$ & $\begin{array}{c}0.26 \\
(0.84 \%)\end{array}$ & $\begin{array}{l}0.26 \\
0.26\end{array}$ & $\begin{array}{l}0.95 \\
0.95\end{array}$ & $\begin{array}{c}0.29 \\
(0.86 \%)\end{array}$ & $\begin{array}{l}0.31 \\
0.31\end{array}$ & $\begin{array}{l}0.90 \\
0.90\end{array}$ & $\begin{array}{c}0.31 \\
(0.85 \%)\end{array}$ & $\begin{array}{l}0.32 \\
0.32\end{array}$ & $\begin{array}{l}0.94 \\
0.94\end{array}$ \\
\hline $\begin{array}{l}\text { Length of } \\
\text { double support } \\
\text { phase }\end{array}$ & $\begin{array}{l}\text { percent of } \\
\text { cycle time }\end{array}$ & $\begin{array}{c}0.17 \\
(0.52 \%)\end{array}$ & 0.18 & 0.97 & $\begin{array}{c}0.12 \\
(0.63 \%)\end{array}$ & 0.14 & 0.94 & $\begin{array}{c}0.11 \\
(0.54 \%)\end{array}$ & 0.11 & 0.96 \\
\hline Cadence & step/min & $\begin{array}{c}0.71 \\
(0.82 \%)\end{array}$ & 0.73 & 0.91 & $\begin{array}{c}0.73 \\
(0.82 \%)\end{array}$ & 0.75 & 0.91 & $\begin{array}{c}0.84 \\
(0.72 \%)\end{array}$ & 0.85 & 0.93 \\
\hline Step length & $\mathrm{mm}$ & $\begin{array}{c}2.91 \\
(0.66 \%)\end{array}$ & 3.01 & 0.97 & $\begin{array}{c}3.07 \\
(0.48 \%)\end{array}$ & 3.15 & 0.98 & $\begin{array}{c}4.61 \\
(0.57)\end{array}$ & 4.67 & 0.98 \\
\hline $\begin{array}{l}\text { Stride length } \\
\text { Stride length }\end{array}$ & $\begin{array}{l}\mathrm{mm} \\
\mathrm{mm}\end{array}$ & $\begin{array}{c}5.19 \\
(0.59 \%)\end{array}$ & 5.23 & 0.98 & $\begin{array}{c}5.34 \\
(0.43 \%)\end{array}$ & 5.47 & 0.98 & $\begin{array}{c}7.98 \\
(0.49 \%)\end{array}$ & 8.11 & 0.98 \\
\hline
\end{tabular}

1 With our measuring method, the motion of the upper and lower limbs does not hide the markers, the motion is more comfortable.

2 The positioning of the investigated points has no effect on the results.

3 Gait analysis can be obtained not only for few gait cycles but also for a number of gait cycles, providing additional information.

4 The measurement and the post-processing procedures are fast and easy to perform, no time is required for setting and calibration.

5 The price of the measuring instrument and the cost of measurement (less outgoing time for measurement) are lower than those of a complex gait analysis system.

The simplified gait analysis technique presented can be used in several clinical applications, such as outcome evaluation after different orthopaedical, rheumatological, neurological diseases, and monitoring of the rehabilitation process. The measuring method is used at the Motion Laboratory of Szolnok Hospital (Hungary).

\section{References}

1 Alton F, Baldey L, Caplan S, Morrissey MC, A kinematic comparison of over ground and treadmill walking, ClinBiomech 13 (1988), 434-440. PII \$0268-0033(98)00012-6.

2 Bejek Z, Illyés Á, Paróczai R, Kiss RM, Kinematics of knee replacement in patients during gait, Proceeding of the $4^{\text {th }}$ IASTED International Conference on Biomechanics BioMech 2006 Palma de Mallorca, 2006.
3 Bejek Z, Paróczai R, Illyés Á, Kiss RM, The influence of walking speed on gait parameters in healthy people and in patients with osteoarthritis, Knee Surgery Sports Traumatology Arthroscopy 4 (2006), 612-622, DOI 10.1007/s00167-005-0005-6.

4 Jurák M, Kocsis L, Measurement method and calculation package for gait analysis using instrumented treadmill, Proceedings of the third conference on mechanical engineering, Budapest, 2002, pp. 372-380.

5 Kiss RM, Verification of determiningg the spatial position of the lower extremity by ultrasound-based motion analyser, Periodica Politechnica Ser. Civ. Eng 51 (2007), 39-43, DOI 10.331/pp.ci.2007-1.06.

6 Kiss RM, Illyés Á, Comparison of gait parameters in patients with total hip arthroplasty following direct lateral and antero lateral surgical approach, Proceedings of the 6th IASTED International Conference on Biomedical Engineering BioMED 2008 Innsbruck, 2008.

7 Kiss RM, Kocsis L, Knoll Zs, Joint kinematics and spatial temporal parameters of gait measured by an ultrasound based system, Medical Engineering \&Physics 26 (2004), 611-620, DOI 10.1016/j.medengphy.2004.04.002.

8 Kocsis L, More precise measurement method for gait analysis., Proceedings of the third conference on mechanical engineering, 2002, pp. 843-847.

9 Knoll Zs, Kiss RM, Gait pattern of professional fencers., FACTA UNIVERSITATIS Series Physical Education (University of Nis) 1 (2003), 33-41. UDC 796-86:421.

10 Knoll Zs, Kiss RM, Kocsis L, Gait adaptation in ACL deficient patients before and after anterior cruciate ligament reconstruction surgery, Journal of Electromyography and Kinesiology 14 (2004), 287-297, DOI 10.1016/j.jelekin.2003.12.005.

11 Magyar OM, Illyés Á, Knoll Zs, Kiss RM, Effect of medial meniscectomy on gait parameters, Knee Surgery Sports Traumatology Arthroscopy 16 (2008), 427-433, DOI 10/1007/s0167-007-0430-9.

12 Matsas A, Taylor N, McBurney H, Knee joint kinematics from familiarized treadmill walking can be generalized to over ground walking in young unimpaired subjects, Gait and Posture 11 (2000), 46-53. 